\title{
Hemorragia alveolar por consumo de cocaína
}

\section{Cocaine-induced alveolar hemorrhage}

\author{
Javier Enrique Fajardo-Rivero, Kristhel Andrea Neira-Triana • Bucaramanga (Colombia)
}

DOI: https://doi.org/10.36104/amc.2020.1483

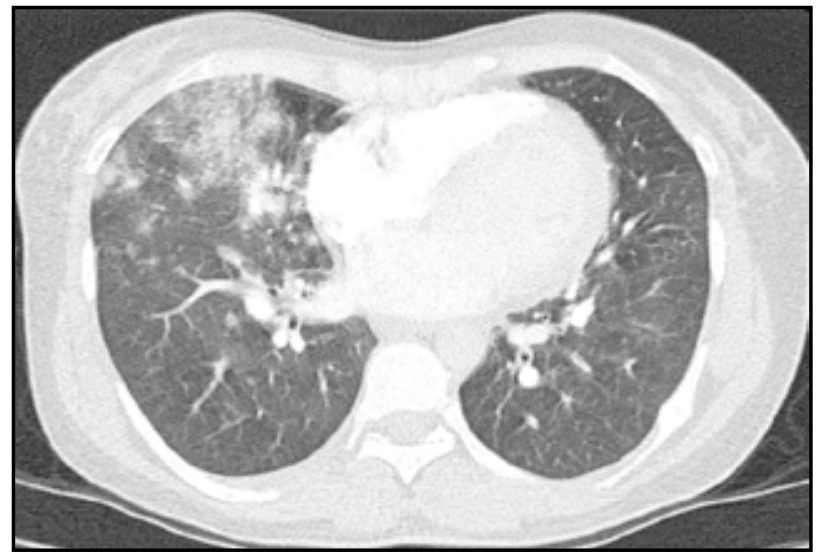

Figura 1. Imagen de tomografía de tórax de alta resolución en proyección axial ventana para pulmón, con evidencia de opacidades alveolo - intersticiales en lóbulo medio.

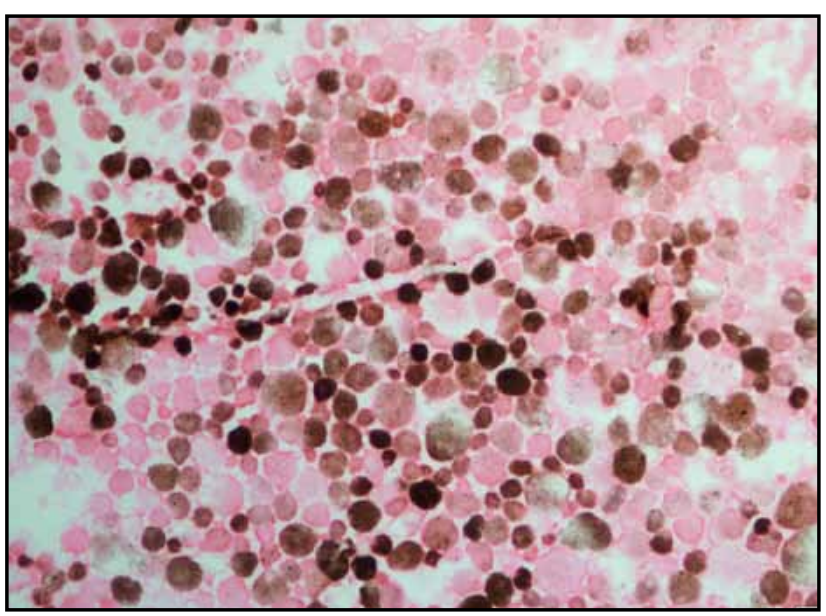

Figura 3. Citología del lavado broncoalveolar con presencia de numerosos macrófagos con pigmento café intracitoplasmático (Hemosiderófagos).

Dr. Javier Enrique Fajardo-Rivero: Médico Neumólogo Universidad de La Sabana. Neumólogo Hospital Universitario de Santander. Docente Universidad Industrial de Santander; Dra. Kristhel Andrea Neira-Triana: Médico Cirujano Universidad Industrial de Santander. Bucaramanga (Colombia). Médico General Fundación Oftalmológica de Santander (FOSCAL), Floridablanca (Colombia).

Correspondencia: Dra. Kristhel Andrea Neira-Triana. Bucaramanga (Colombia).

E-mail: kristhel.an@gmail.com

Recibido: 26/VIII/2019 Aceptado: 13/IV/2020

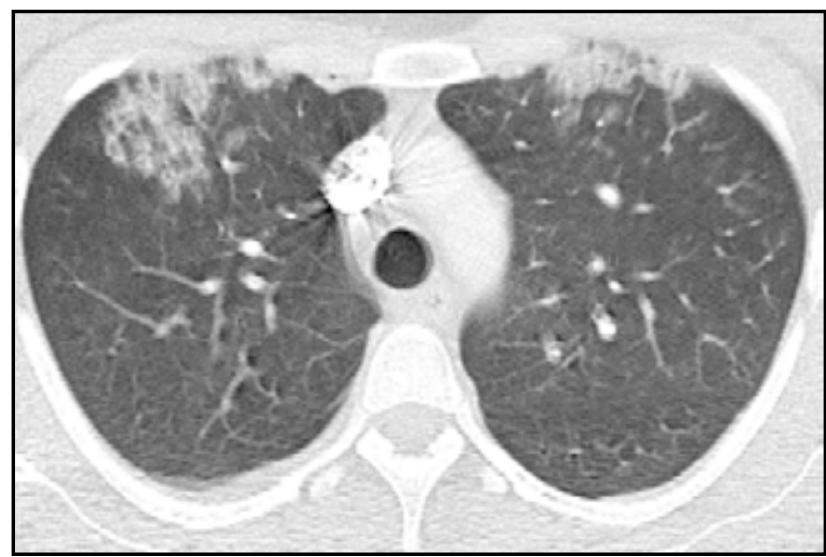

Figura 2. Imagen de tomografía de tórax de alta resolución en proyección axial ventana para pulmón, con presencia de opacidades alveolo - intersticiales en segmentos anteriores de los lóbulos superiores.

Mujer de 28 años, con antecedente de asma bien controlada, consumo de 15 cigarrillos diarios desde los 10 años, alcohol y de basuco (base sucia de cocaína) desde los 12 años. Cuatro horas después del consumo de basuco, debuta con disnea, tos con expectoración hemoptoica, sumado a estertores gruesos, VIH negativo. Tomografía de tórax con opacidades alveolointersticiales periféricas en lóbulos superiores y medio. Estudio histopatológico lavado bronocoalveolar mostró numerosos hemosiderófagos, asociado a focos de hemorragia pulmonar.

El pulmón de crack es un síndrome pulmonar agudo, que se presenta después del consumo de crack-cocaína y se considera una complicación rara y potencialmente fatal. El diagnóstico es clínico, imagenológico y recuento significativo de hemosiderófagos en relación a hemorragia pulmonar $(1,2)$. El tratamiento consta en retirar el consumo de la sustancia tóxica. El uso de corticoesteroides sistémicos, es controvertido $(1,3,4)$. En nuestra paciente se usó corticoesteroide inhalado obteniéndose un desenlace satisfactorio.

\section{Referencias}

1. Haim DY, Lippmann ML, Goldberg SK, Walkenstein MD. The pulmonary complications of crack cocaine. A comprehensive review. Chest. 1995;107(1):23340.

2. Terra Filho M, Yen CC, Santos Ude P, Muñoz DR. Pulmonary alterations in cocaine users. Sao Paulo Med J. 2004;122(1):26-31.

3. Forrester JM, Steele AW, Waldron JA, Parsons PE. Crack lung: an acute pulmonary syndrome with a spectrum of clinical and histopathologic findings. Am Rev Respir Dis. 1990;142(2):462-7.

4. Gatof D,Albert RK. Bilateral thumb burns leading to the diagnosis of crack lung Chest. 2002;121(1):28991. 